\title{
On Profit Mode of Chinese Traditional Paper Media in Digital Age
}

\section{Fangfang Yang}

Department of Management, Guangdong AIB Polytechnic College, Guangzhou City, 510507, China

ffyang@gdaib.edu.cn

Keywords: Traditional Paper Media, 4P Marketing Strategy, Profit Model

\begin{abstract}
Under the impact of the new media, advertising revenue of the traditional media are undergoing a sharp decline. The excessive reliance on advertising revenue is now becoming the Achilles heel of the traditional paper media. Therefore, it is imperative to get rid of the dependence on the advertising revenue, and innovate the profit mode for the traditional paper media in the digital age. This work is to seek out the profit sally port of the traditional paper media from the perspective of the 4P marketing strategy.
\end{abstract}

\section{Introduction}

"High risk, high reward", it is exquisite to elaborate the relationship between the traditional paper media and the advertising revenue. The income of traditional paper media mainly stems from two sources, namely, circulation and advertising revenue, the later accounts for over $90 \%$ of the total, that is the profit mode of traditional paper media. Generally, the profit mode includes the following elements: profit source, size and stability. This profit mode has been consistently effective due to a relatively stable source and sustainable growth untill the rise of the new media. The situation underwent an upheaval due to precarious profit source and narrowing profit size, i.e. at bottom, the advertising revenue accounting heavily of the total income now drops continuously and sharply. Statistics indicated that, in 2013, the advertising revenue of China's traditional media remained within the downward channel, thereinto, the advertising revenue of the newspaper has decreased by $9.17 \%$ compared to that of 2012. In stark contrast, the online advertising revenue of the new media in 2013 has almostly doubled that of 2012, with a growth rate of up to $45.85 \%$. All indications manifest that the profit area of traditional paper media has been changed dramatically in quiet. The new media is becoming more and more dominant, into which the investments are continuously introduced by the advertisers who have ever invested in the traditional paper media. As is shown in Figure 1 and Figure 2, the scale of online advertisement is continuously increasing while the newspaper advertisement scale is downward. And the excessive dependence on advertising revenue is now becoming the Achilles heel of the traditional paper media. Therefore, it is imperative to innovate the profit mode of the traditional paper media in the digital age.

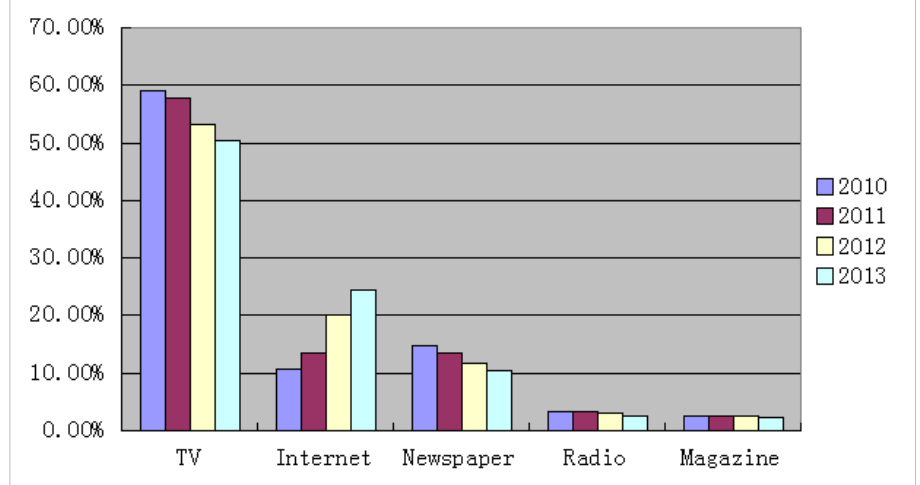

Figure 1 Media Distribution of China's Advertising Market of 2010-2013

(Note: All the data come from SOURCE EnfoDesk (C) Analysys International) 


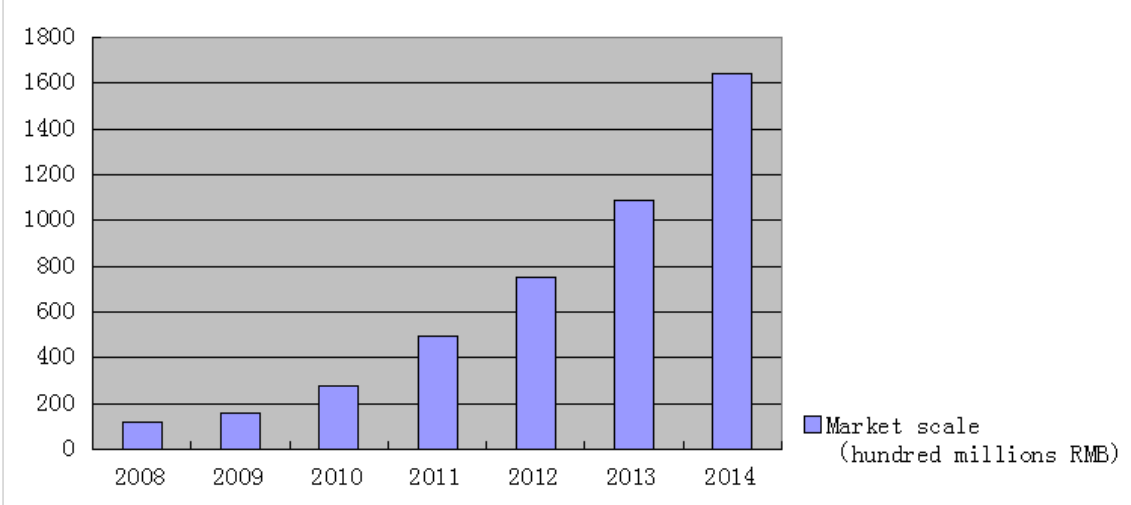

Figure 2 Scale of China's Online Advertising Market of 2008-2014

(Note: All the data come from SOURCE EnfoDesk (c) Analysys International)

MacCarthy - US marketing master, has proposed the famous 4P marketing strategy in the 1960s. The so-called 4P refers to "Product", "Price", "Place" and "Promotion". MacCarthy believes that all marketing activities shall embrace the four inseparable elements. $4 \mathrm{P}$ is applicable to all industries, where the paper media is no exception. So to speak, the "Product", "Place" and "Promotion" of 4P are ultimately aimed at the price, i.e. the profit. Thus, this work is to seek out the profit sally port of the traditional paper media from the aspects of the three elements respectively.

\section{Product: utilize USP, act as content providers}

Rosser Reeves - US advertising master in the 1950s, has proposed a momentous advertising concept - USP, i.e. unique selling proposition, which includes three main points: a) a proposition to the consumers shall be included in the advertisement, i.e., the benefit of purchasing product; b) the proposition shall be unique, i.e., it is owned solely, no competitor can propose or has ever proposed it; c) this proposition must be strongly persuasive in encouraging purchase. For traditional paper media, the USP is exactly the "differentiated content" and that is where the core value lies. Before the rise of the new media, the content of traditional paper media makes profits by "twice selling", i.e. sell the content to the readers firstly, and then sell the readers to the advertisers, forming a double-customer profit mode. However, the rise of the new media voilently shakened the profit mode which was once reasonably stable. Because the new media changed the way people read and information-receiving, with the popularity of the computers and smart phones, people are increasingly used to reading news and information via mobile phones, IPAD, or the computer.

Traditional "readers" are now transforming to "users", while the user volume is the slam-dunk for all big business information portals. Now the paper media readership is decreasing, while the commercial site users are increasing, indicating that the profit area is now transferring from the paper media to the network. To cater the change of information-receiving ways, numerous paper media are now seeking to publish paper contents online to realize digitalization. However, to their embarrassment, many newspaper industries are spiraling toward the plight of "endless input without output", there are two reasons: firstly, the so-called "digitalization" of most paper media simply transfer the paper content to the websites. Compared to the commercial web portals with expertised technology platform, there is no comparability of the user volume between the newspaper self-built website and the commercial web portals with expertised technology platform, the former is even not in the same league as the latter; secondly, it turns out to be impossible for the newspaper industry to make profits by circulation, beacuse the information is easily obtained through the internet. On this point, Adam Smith has proposed a famous value paradox in The Wealth of Nations, the main point of which is "Water is cheap for abundance, while diamond is precious for scarcity". The mobile news and self-built websites of paper media are not profitable, just because the information embraced is too abundant, say nothing of scarce. The electronic versions of many paper media can be described as the free exposure of paper contents, because when the electronic version is released 
online, all major search engines and web portals would soon build access to it, that is to say, the paper contents are freely provided to the search engines and web portals. Meanwhile, the readers are enjoying free reading. So to speak, the audiences could now freely enjoy the paper contents which should have been paid for, that's where the profits loses. The solution is to withdraw the free channels, and provide contents with charges for different audiences:

For commercial portals and search engines: change "twice selling" into "thrice selling ".Comparing with the traditional newspaper industries, the commercial portals have owned an absolute advantage in online news communication due to its huge user volume currently. However, it has a fatal weakness, i.e., the existing laws and regulations forbit them to collect news by self, and the news sources have been strictly limited, offering the policy support for newspapers to provide business websites with paid news. Moreover, the self-advantages of newspaper content can provide the technical support, because the brand content is just the core technology of newspapers.

One optional cooperation model of the traditional paper media and the commercial websites is content-packaging sales or customization sales, i.e., tailoring the content in conformity to the needs of the commercial websites, such as the "Special for Sina", "Special for NetEast" or "Special for Sohu", etc. Conversly, in line with the requirements of the website news classification, these commercial websies can also demand "Special Supply from Southern Weekly" for news of current political affairs, "Special Supply from Southern Entertainment Weekly" for entertainment news, and special supply from one magezine for special coverage, and ensure its professionalization in news sources with the help of the brand influence and credibility possessed by paper media. As to the profits of the newspapers, one can offer a one-time buyout, or increase/decrease by hits.

For ordinary users: perform market segments, tailor mobile news. For the ordinary users, the newspaper industry also can follow suit, tailor mobile news for different users, as to realize transformation from paper media to mobile news. However, the profit mode of mobile news differs form traditional paper media. Firstly, it is hard to release advertisements on the mobile screens due to constrained space. Secondly, the operator is playing all cards to restrict advertisement to maintain user volume. Thus in order to make profits through mobile news, the paper media have to cooperate with the big mobile operators in the same way as with the commercial websites. In this regard, West China Mobile News is a successful case, which has made a great profit nowadays through combination of market segment and customization. E.g., for Mobile users, it has released 7 versions of mobile news, i.e., City Version, Movement Version, Sports Lottery Version, Campus Version, Security Version and Convenient Information, etc., for Unicom users, it has released 5 versions, i.e., Essence Version and Fashion Version, etc., as for Telecom users, is has released 3 versions such as Bulletin. Each version has its unique charateristics in forms and content, covering users of all levels. Based on their brand influence and credibility, each newspaper industry could cooperate with each big operator, perform market segments, and tailor the mobile news for different users. E.g., for business group, one can release a Business Version, and for the white-collar group, one can release a Urban White-collar Version, or release corresponding mobile new according to different classifications of users such as Antizen, Wave Gens, etc.

For entity, enterprises and organizations: provide customized newpapers. Besides offering the customized content to the online users, the offline audiences shall not be neglected, i.e. the entity, enterprises and organizations. Every enterprise has its own corporate culture, which is an indispensable part of brand construction. It means that the enterprise culture service is a huge market, for which, the newspaper group can exert their content and communication advantages, and launch a culture customization service department or company to customize enterprise newspapers and cultural activities for local enterprises and institutions. For enterprises and institutions, firstly, the professionalization of the enterprise newspaper is guaranteed by the experience and brand of newspaper industry; secondly, their brand image can get promoted by the newspaper's good brand credibility and influence. Conversly, for the newspaper, this sort of cooperation can act as an income source, as well as a link for better interactive advertising cooperation relationship between 
the enterprises and the newspapers. In sum, it is a win-win initiative for both the enterprises and the newspapers.

\section{Place: extend industrial chains, exploit new profit area}

As was said by a newspaper CEO, "It is not who lives better but who lives longer that counts." Though it is a joke, it is indeed the time for the traditional media to seek for profit channels other than the advertising revenue and stop putting all the eggs into one basket, for which, the traditional paper media shall not only merge with the new media, but also refer to the profit mode from the new media. Because the profit of the new media is based on a system rather than a single product, e.g., Tencent QQ, as an instant online chat tool, QQ itself is not profitable, anyone can freely register and use, but Tencent can make profits by other means, such as QQ show, Qzone, QQ pets, QQ VIP, online game, etc. The advertising revenue of which is less than half of its total income. Newspapers shall learn from the new media in this point, reduce the proportion of the circulation and advertising in total income, but to seek for a new profit area, so to reduce operational risks:

“Consider Benefits of the Small”: Develop Community Newspapers. In the 1960s, in view of the common pursuit of the flashy in the then US automobile markets, William Bill Bernbach - the creative director of US advertising company DDB has created a series of advertisement with a theme of "Consider benefits of the small" for Volkswagen Beetle in the way of reversing demands, and successfully opened the market door with one hit. The success of Volkswagen Beetle hinges on not going with the flow, but in the opposite direction, looking for market gaps and occupying it.

The community newspaper is similar with the Beetle car: small, less circulation and pragmatic, that is the reason why the community newspaper was unknown to fame. Joke Lauterer - the founder of the community news section of US news media conference, believes that there even does not exist one community newspaper currently in China in real sense. Indeed, the community newspaper is a marginal product, compared to the mainstream newspapers, because it seems to be for pure public service, with no profit and limited influence. Actually it is not true. Upon closer inspection, there are a mass of hidden business opportunities and potential inside community newspaper. Statistics indicate that, in the first half of 2013, the total national newspaper sales fell by $8.87 \%$, which was record high, it was worse in the second half year, by the end of December, it fell by $2.16 \%$ (compared to the first half of 2013), and fell by $10.83 \%$ (compared to the second half of 2012). In a whirl of declines, only the communist party newspaper, community newspaper and the current politics newspaper underwent a rise. But in the US, the community newspaper is developing smoothly, which accounts almost $97 \%$ of the total circulation of US newpapers, and the overall income of community newspaper is three times as much as the key newspaper, as was indicated by the data of 2011 from the US Newspaper Association. In this case, the community newspaper is very promising to act as a new profit source of the newspaper industries.

Exert Effect of Industry Linkage , Take a Diversified-development Road. To be independent of advertisement, the traditional paper media must extend their product chains and take a diversified-development road, in which respect Rayli magazine is a successful case. Rayli magazine initiated in a fashion magazine, later started to undertake the model brokerage business by organization of Rayli Cover Girl Contest. Amid in the fashion circle, Rayl takes "understand fashion, being in fashion” as its unique selling proposition (USP). As an extensive concept, fashion is associated with many industries such as entertainment, electronics, clothing, suitcase\&bag, jewelry, etc., all of which can be exploited as the extended chain of Rayli as long as they have something in common with Rayli in positioning or disposition.Referring to Rayli, Nanfang Metropolis Daily managed by Nanfang Media Group, with all themes focusing on "Metropolis", have too many associated industries with metropolis, such as delicacy, entertainment, tourism, shopping, automobile, real estate, etc., all of which can be developed as product chains.

While the newspaper industries are expert at "information", they can exert to the fullest their abilities of information collection, organization and spreading, cooperate with governments, integrate relevant resources such as tourism, ticket affairs, hotel, catering, taxi, local special gifts, establish a brand of China's official tourist information service center, exhibit some DM pamphlets 
at the entrance/exit of airports, railway stations and bus stops and spread them in forms of advertisement. In China, the privately-owned tourist agencies may have similar functions with officially-owned volunteer service stations, but neither of them have complete functions, nor effective influence, and the credibility of which is far from enough. Therefore, along with the sustainable and rapid development of China's tourism, it is very promising to build a reliable Chinese i-SITEs with high credibility.

\section{Promotions: cross-boundary cooperation, event marketing}

In economics, the profit is generally divided into normal profit and innovative profit. If circulation and advertisement boil down to the normal profit, then sales promotion belongs to innovative profit. The promotion approaches can be adopted regardless of normal or innovative profit zone. The promotion approaches of normal profit zone of traditional paper media are more or less the same, which are nothing but gift promotion, education marketing, roadshow, horizontal alliances, etc, Except for horizontal alliances, all of them belong to the category of price war, which raise circulation and popularity by price reduction or disguised price reduction (e.g. offer free gifts). For example, during all paper media in UK took advantage of the Scottish independence referendum happened in September, 2014, to participate promotion wars while expressing their appeal and stance. However, the price war is one of the lowest strategies due to its easy replication, and non-premanence. A reproducible strategy can never be an ideal strategy. Therefore, in order to break through the market turmoil, the policy makers of traditional paper media shall consider starting from innovating the forms of horizontal alliances and the promotion of innovative profit zone.

Model Innovation, Cross-boundary Cooperation. As the name implies, "horizontal alliances” generally refers to "Two enterprises or brands with similar strength but from different industries, accomplish certain marketing target and create market interests with mutual benefits via collaboration". For traditional paper media, the "horizontal alliance" is not a fresh term, but it is often used as an approach of circulation promotion. For example, Nddaily managed by Nanfang Media Group once ever cooperated with mobile phone operators to promote by "charge calls, delivering free newspaper" or "subscribing to newspapers, charge calls for free". Recently, the cooperation between newspaper industry and e-commerce is prevailing. For example, Wenzhou Evening News has made a success in this respect, which set a precedent in a lot of aspects among all the newspaper industry in China via consociation with Taobao, Alibaba Cloud Computing, China Mobile, etc. As it were, Wenzhou Evening News has made a certain exploratory achievement and accomplished considerable economic benefits in a short time in the horizontal alliance between newspaper industry and e-commerce.

To speak bluntly, horizontal alliances are a type of cross-boundary cooperation. The cross-boundary cooperation object of the newspaper industry is far from enough which is restricted to e-commerce. Besides the e-commerce, the newspaper industry is strongly suggested to develop in-depth towards the new media. The alliance between TCL and Baidu as well as IQIYI in 2013 is a nice example, which creates a new form of cross-boundary cooperation between appliance and internet industry. Anyone who buys TCL color TV sets can enjoy watching all programs of iQIYI permanently for free. It is extremely attractive for the increasing Chinese netizens, which is fastly increased as shown in Figure 3. As is said by Li Dongsheng, CEO of TCL, "China has 0.4 billion netizens born in the 80s or 90s, who has been growing up along with the internet development, thus demanding significantly for video content, but have not been satisfied yet.” 


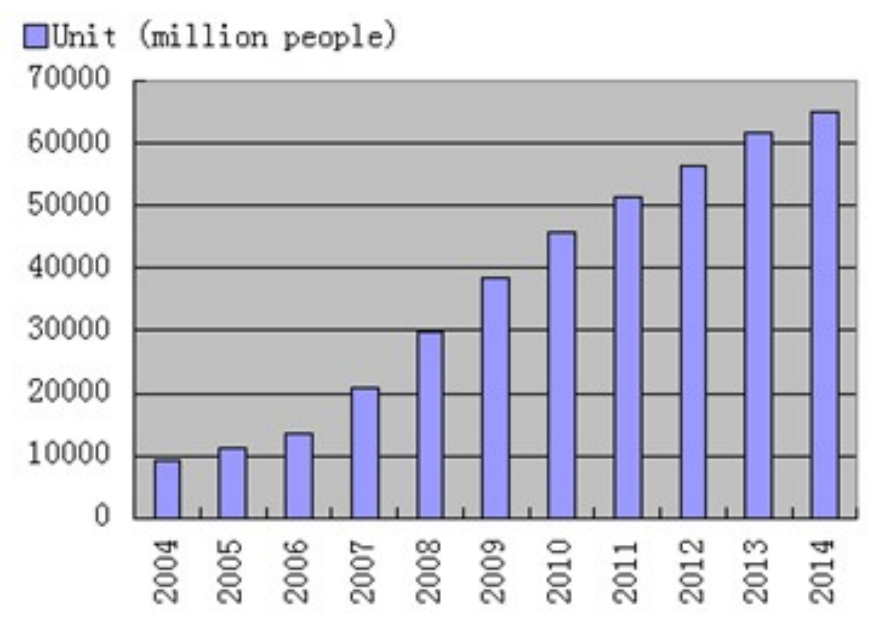

Figure 3 Scale of Chinese Internet users of 2004-2014

(Note: All the data come from China Internet Network Information Center CNNIC)

Brand Extension, Event Marketing. In fact, the traditional paper media have already participated in the promotion of innovative profit zone for long, i.e. the event marketing. E.g. Southern Metropolis newspaper series managed by Nanfang Media Group, its branch - Southern Metropolis Weekly often holds a variety of enterprise forums and summit meetings. And Southern Metropolis Entertainment Weekly has positioned itself to be "Platform No.1 of China's Entertainment Marketing Integration”, and held various activities associated with this positioning and entertainment periodically every year, such as “Opening Ceremony of Star Citizen”, “China's Entertainment Promotion Marketing Awards”, Jin Rong Tree Film Festival, selection of annual entertainment personality or public welfare entertainment stars, etc. And Southern Weekly which is serious in positioning are now attempting to cooperate with TV media. E.g., it has cooperated with Sichuan TV to some relatively serious but intelligence-competing programs such as I know in 2014.

In essence, the event marketing of traditional paper media is bound up with its profit growth point and extending product chain. E.g., the as-mentioned community newspaper development, one can promote in forms of brand sponsorship or title sponsorship for holding a lot of community activities with different themes, such as community flea markets, health seminars, community sports contests, community friendship activities, as well as such theme activities as pets, flowers, tea, chess, photography, poem creation, etc., which can enrich the community life as well as promote the newspaper brand. And the as-mentioned building of China's official tourist information center, e.g., one can organize the promotion activities with brand naming sponsorship on a regular basis, such as "XXX Tourism Culture Festival”, "XXX Car Renting Festival”, "XXX Hotel Exhibition and Sales Meeting", or hold the award selections and contests such as "China's Most Beautiful Villages”, "Discovery of Tourist Spots With Best Tradition Conservation”, or cooperate with certain brands (e.g. automobile) to organize "XXX Expedition". During organization of these activities, the traditional paper media can take advantage of circulation to make online and offline interaction, and create a stereoscopic effect of circulation.

\section{Conclusions}

As was said by a Chinese proverb, "The methods used may vary, but the principle is the same." Another one proverb says, "A man shall cope with changing events by sticking to a fundamental principle." For the traditional paper media, differentiated content quality is the "principle" to be adhered to both in the past and at present. Although people's reading manners are changed in the digital times, so are the rivals, spreading technologies, platforms, manners. Anyhow, people still need news and reading in spite of all changes, i.e, the market still exists, only the market environment has been changed. Where there is a market, the marketing $4 \mathrm{P}$ would play its role. Therefore, as long as the traditional media persist in bettering their own products, adjusting profit-making models properly, following the trend and changing their communication approaches 
with target audiences, the prospect will not be as passive as predicted by some industry insiders, on the contrast, they may survive vigorously in a new manner. This work is to seek out the new profit mode of the traditional paper media in China from the perspective of the 4P marketing strategy.

\section{References}

[1] Adrian, J. S., David, J. M., Bob, A. (2002) 'The Profit Zone’, Crown Archetype: New York.

[2] Rosser, R. (1961) 'Reality in Advertising', Knopf: New York.

[3] Roger E.B. (2002) ‘The Penguin History of Economics’ Penguin U.K.: London.

[4] William, D.P., E. J.M. (2007) 'Basic Marketing: A Global-Managerial Approach. 16th Edition' McGraw Hill: New York.

[5] Leung, L,. Fung, A., \& Lee, P. S. N. EDS. 2009. Embedding into Our Lives: New Opportunities and Challenges of the Internet. Hong Kong: Chinese University Press.

[6] Al Ries, Jack Trout (2001), 'Positioning: The Battle for Your Mind ', McGraw-Hill; 1 edition.

[7] Chip Heath , Dan Heath (2007), 'Made to Stick: Why Some Ideas Survive and Others Die ', Random House; 1st edition.

[8] Chip Heath , Dan Heath (2010), 'Switch: How to Change Things When Change Is Hard ', Crown Business; 1 edition.

[9] Lee, P. S. N,. Leung, L,. \& So, C. Y .K. Eds. 2004. Impact and Issues in New Media: Toward Intelligent Societies. Cresskill, NJ: Hampton Press.

[10] Yijin Fan. (2006). The Strategy of Nanfang Daily. Nanfang Daily Press. In Chinese. 